\title{
FAMILIA Y JÓVENES EN UN MUNDO QUE CAMBIA: ¿QUÉ PROVOCACIONES DE Y PARA LA PASTORAL VOCACIONAL?
}

DOI: https://doi.org/10.52039/seminarios.v49i169.806

Autor: Sergio Lanza. Presidente del Instituto Pastoral en la Pontificia Universidad Lateranense.

(Tradujo del original italiano D. Germán González Domingo)
En este mundo nuestro en continuo cambio es preciso dejar la nostalgia con respecto a relaciones anteriores $y$ abrimos a una consolidación de la familia cristiana, a generar confianza en los jóvenes y trabajar el horizonte cultural con una pastoral de acogida y con propuestas fuertes.

El tema evidencia tres segmentos: vocación, familia, jóvenes. Cada uno de ellos es un mundo; no es posible en una relación breve explorar todo este territorio, ni siquiera bajo el aspecto específico de la relación que es el de las provocaciones, de las instancias que la pastoral registra pasiva y activamente, recibiéndolas o promoviéndolas o respondiendo a ellas, en relación a estos ámbitos sensibles. Por tanto, la exposición se ve obligada a hacer una elección. El intento es ofrecer elementos significativos, sabiendo que muchos quedan sin tocar.

La primera observación es que estos segmentos no están vinculados de una manera ocasional. Es verdad que se pueden abrir otros, como suele hacerse en la navegación mediática, informática, se pueden abrir otros link... Lo que estos segmentos dicen es que su correlación es irrenunciable. Un trinomio que puede convertirse en un polinomio marcado por la inclusión recíproca, por lo cual la disminución de uno de estos aspectos incide en equilibrio de todos los otros.

La relación parte haciendo referencia en sentido de horizonte -pero muy rápidamente con sólo alguna cata, alguna breve profundización- a la situa- 
ción, al mundo que cambia; para después detenerse sobre la familia y los jóvenes, en relación a la vocación y consiguientemente a las responsabilidades eclesiales en este punto.

Y la Gaudium et spes -principalmente en el número 54, pero también en otros textos- consideraba nuestra época como época de cambio. Lo han tematizado nuestros obispos en el Documento del decenio. Es una constatación tan evidente que puede darse por descontada, así como la enumeración de tantos signos positivos y al mismo tiempo problemáticos y negativos, que comporta este cambio. Pero es necesario afirmar la exigencia de profundizarlo, de no contentarse con diagnósticos fáciles. Los encontramos repetidos, un poco deprisa; se les puede dar un montón de nombres: desde la secularización para arriba, hay una serie de etiquetas que esconden, a veces, la inexistente falta de contacto real con nuestro tiempo. Se asemeja a ciertos diagnósticos de los médicos que no hacen otra cosa que poner un nombre difícil a un malestar que no se sabe curar. Entonces a uno le duele la cabeza y va al doctor, y este le dice: "Es una cefalea, una jaqueca en racimos...", ¿ise siente mucho mejor, después!?... Este es el riesgo que nosotros corremos. Entonces, querría decir algunas cosas no repitiendo -si es posible- lugares comunes. Sobre todo evidenciando la postura, en claroscuro, a través de algunos riesgos.

Existe el riesgo de perseguir el cambio, siempre preocupados para ir "al compás de los tiempos", como se dice, entrando en esa síndrome del adaptarse que es la fuente de los malestares, de las insatisfacciones: el que se adapta nunca está demasiado contento. Está contento el que está en el puesto que le corresponde; está contento quien se pone el traje a medida, quien se pone uno arreglado está menos contento. Recorriendo, pues, el tiempo afanosamente, arriesgándose además a acomodarse al tiempo mismo y no cae en la cuenta de que contrae los virus y las patologías del tiempo.

Desde otro punto de vista, también existe otro riesgo: el decir que además las cosas no son tan distintas como antes, sobre todo si en esto nos referimos a Italia: "Pero Italia no es como los otros países calamitosos, donde todo se malogra... nosotros tenemos todavía tanta gente que practica..." ...jes verdad, quizás! -es un juicio difícil de dar-, pero me parece que es como intentar esconderse detrás de un dedo. Italia tiene sus valores; pastoralmente hablando es una nación viva y vivaz - gracias a Dios y a los que trabajan en esto- pero tiene sus problemas. Sobre todo, estos problemas son del mismo signo, si bien no tienen idéntica fisonomía, que los que vemos en otras realidades del mundo occidental, desgraciadamente más abandonadas, pastoralmente hablando, que las nuestras. No hay que dormirse en los laureles.

Así pues, el tema vocacional es uno de los que ha hecho sonar la alarma. Alguno todavía se está desperezando, todavía está bostezando, pero le queda poco tiempo para hacerlo, porque dentro de diez años también estos 
que aún no se han despertado tendrán que hacerlo, ¡inexorablemente! Hay, pues, que evitar los diagnósticos facilones y cómodos. Por otra parte, nadie de nosotros quiere asociarse a los profetas de desventuras, ni caer en el pesimismo, que es absolutamente contrario a la fe cristiana, que -como recordaba el papa, evocando esta expresión de Juan XXIII- tiene el tono de la esperanza, que nunca decae. El juicio pesimista es la antecámara de la retirada, de la pastoral de resignación, de esa que se despereza en las lamentaciones. Digo siempre que la pastoral escribe con mucha frecuencia páginas inútiles de dos libros inútiles. Uno lo ha recordado antes don Luca Bonari, el de las "buenas intenciones", el otro es el "de las lamentaciones": ni uno ni otro sirven. Creo que este Congreso no pretenderá añadir páginas a estos dos libros ya excesivamente gruesos.

En realidad, se trata de hacer resonar la palabra del evangelio, esto, de la Buena Noticia, en este mundo que cambia, teniendo el coraje -y cito la Evangelii nuntiandi, número 19- de «alcanzar y transformar con la fuerza del Evangelio los criterios de juicio, los valores determinantes, los puntos de interés, las líneas de pensamiento, las fuentes inspiradoras y los modelos de vida de la humanidad, que están en contraste con la Palabra de Dios y con el designio de salvación». Dicho así suena hasta bien. Hacerlo, pasar del objetivo al como, ciertamente es una empresa de compromiso importante, de gran empuje. Porque este tiempo nuestro presenta caracteres que exigen solicitar una atención muy vigilante, muy fuerte, ciertamente preocupada aunque no inquieta. Entro ahora en una profundización rapidísima de carácter general, antes de pasar a los específicos de la temática propuesta.

\section{Factores relevantes}

\section{La pérdida del centro}

Es fácil constatar que no vivimos en una sociedad de tipo cristiano, y de todos modos no vivimos en una sociedad de tipo homogéneo. Vivimos en una sociedad fragmentada. Habréis encontrado esta observación mil veces. Inmediatamente esto tiene una exigencia: es una instancia, es una provocación, de lo contrario nos quedaríamos en el diagnóstico de la etiqueta y en la lamentación de los llorones. Esto significa inmediatamente que la relevancia de la fe cristiana, su significatividad exige marcar la originalidad de su perfil. La fe cristiana no es una fe "contra", pero ciertamente no renuncia de ninguna manera, por una manifiesta aquiescencia, a sus perfiles, a su especificidad. Es verdad que durante siglos ha desarrollado la tarea de religión civil, tantos siglos en los que, en nuestros países, religión y religión católica se identificaban, lo que ha producido una especie de escasa capacidad, casi de reticencia, 
de desamparo frente a todo esto. Estamos muy contentos cuando aparecen y se manifiestan expresiones de religiosidad, pero tenemos también que subrayar - no contraponer- la que es la específica fisonomía de la fe cristiana. No podemos menos de preguntarnos por qué, en una situación que poco o nada se sabe del cristianismo, existen, sin embargo, lugares comunes que persisten obstinadamente. Si no se quiere asistir a las clases de catecismo (además es que las de los jóvenes y adultos son lugares de especie protegida, en vía de extinción..., pero) si no se quiere frecuentar estos lugares, basta con encender la televisión y seguir ciertas transmisiones de encuestas para saber cuanto no se sabe. Preguntad qué es el pecado. Preguntad sobre el concepto de la vida y de la muerte. Preguntad por la concepción de la corporeidad y la sexualidad. Preguntad qué dice la fe cristiana acerca de la creación del mundo en relación a la ciencia. Cito algunos puntos neurálgicos, y encontraréis inmediatamente la persistencia de respuestas que apenas tienen algo que ver con la autenticidad de la fe cristiana.

Una vez más, el testimonio. Aquí emerge la necesidad que dentro de la común dignidad humana, que está en primer plano -lectura del breviario de hoy, el final de la lectura de san Gregorio Nacianceno: la dignidad, el ser cristianos, el nombre de cristianos antes de cualquier otra dignidad y nobleza- las múltiples formas de la vida consagrada, de la vida religiosa, recobren el modo de expresar de una manera significativa la originalidad cristiana, lo que ha de ser su tarea, en su prospección escatológica y en la acentuación de la exigencia -que es de todos, no sólo de ellos- de la práctica fundamental del estilo de la existencia cristiana.

Como se ve, ya de entrada, surgen de aquí tareas específicas. Hay muchísimo que hacer también bajo este aspecto, y hay que recordar que no es necesario conocer todo sobre la comunicación (se habla mucho de ella, pero se sabe tan poco) sino recordar siempre que la comunicación llega cuando la recibe el destinatario. Y hasta entonces no es suficiente decir: «Pero nosotros lo hemos hecho bien. Tenemos la conciencia tranquila. Hemos cumplido con nuestro deber». Si el otro ha entendido otra cosa, tenemos el deber de actuar de tal manera, modificando lo que haya que modificar, para que lo entienda con exactitud. Ha sido también una preocupación para Jesús, a quien muchas veces se le entendía mal. Pero no por eso él ha dicho: «¡Brutos y malos! ¿No entendéis? Peor para vosotros».

Fin de las comunidades estáticas. Otra aspecto de la pérdida del centro. Esto es, la identificación fácil con la comunidad territorial disminuye, no sólo en lo que se refiere a la vida de las comunidades en el territorio, sino en general. Existe una trama múltiple de factores (que aquí no se pueden examinar) pero también esto evidencia un factor que interroga profundamente. La ligazón 
establecida de las vocaciones ministeriales con la territorialidad circunscrita es un punto de fuerza que ha de permanecer, pero no puede permanecer en la exclusividad de esta ligazón territorial circunscrita. Si esta ligazón no se entrelaza, pierde una dimensión típica de la movilidad de nuestro tiempo.

\section{La disipación simbólica}

El nuestro es un tiempo en que los símbolos se han roto, las "grandes narraciones" ya no logran influir en la existencia. He aquí un punto que nos afecta muy de cerca.

Es claro para todos que un punto verdaderamente neurálgico bajo este perfil se da por la pérdida del código de lo sagrado. El código es lo que nos permite entrar dentro de un universo lingüístico, por ejemplo, comunicativo, de comprensión..

Tanto la figura del ministerio ordenado como la figura de la vida consagrada se ha comprendido, integrado, colocado hasta hace pocos años -pongamos la fecha desde 68 para entendernos- dentro del código de lo sagrado. El código sagrado es hoy absolutamente incomprensible de esa forma; habla una lengua desconocida. Es como si uno encontrase un texto de una lengua que no ha sido descifrada. Esta es una de las razones por la que se ha llamado crisis de identidad de las figuras de especial consagración -como se dice habitualmente en el ámbito eclesial-, que no hay que confundir con esas que pueden ser crisis de identidad personales, que es otro capítulo. Es una crisis cultural.

Este aspecto está asociado a otro, a ese por el que la sociedad ha ido organizándose por sistemas autoreferenciales. De una sociedad integrada, en donde las personas pertenecen ante todo a una relación intersubjetiva, y luego pertenecen al mundo de la propia situación, de la propia función, se ha pasado a una sociedad de disección sistémica. Traduzco en italiano. En un pueblo, pero también en una ciudad no grande, en el barrio la gente se conocía por el nombre, tenía relaciones intersubjetivas, después estaba el maestro, el médico, el herrador, etc. todo esto se ha vuelto completamente del revés. Las personas hoy se encuentran, en la gran mayoría de lo casos, en razón de la función que desarrollan. El párroco no es el "fulano de tal", conocido por la gente, porque a lo mejor iba a la taberna a jugar a las cartas, o también conocido porque decía tres rosarios... El párroco es conocido porque ejerce esa función. Hoy, la mayor parte de los parroquianos, salvo en pequeñísimos centros, interpreta las figuras en cuanto funciones, no en cuanto sujetos.

Juntos estos dos factores han dado un golpe mortal a las figuras institucionales en general, y ciertamente a las figuras eclesiales. Un golpe mortal. Hay que darse cuenta de que ciertos fenómenos han llegado por un cambio natural que no es culpa de nadie, pero hay que darse la cuenta de su realidad. 
Esto también es la razón del cansancio, a veces, que esos mismos que están investidos de estas misiones encuentran en el realizarlas, en el interpretarlas, en el codificarlas de nuevo. Y entonces aparece la tentación de reducirse a tarea-función; y por consiguiente de recuperar a la baja una plausibilidad de la propia actividad. Pero dentro de esta recuperación la figura se hace cada vez más diáfana y cada vez menos apetecible. Dicho sencillamente: si el sacerdote se convierte en ese funcionario delegado para determinadas prestaciones, incluso para prestaciones reconocidas y generalmente apreciadas, entonces ¿cuántos jóvenes se sentirán atraídos por esa figura? Digo siempre: pues se oposita a Correos... y tiene menos líos, menos obligaciones, gana más, ¿por qué pues tendría que hacer otra cosa? Si el religioso y la religiosa están cualificados no por su figura, sino por el servicio que realizan, lo único que se percibe es: "Es verdad, cuando estaban las religiosas no miraban al reloj...". Sí, sí, por favor, todas cosas hermosas, un poquito a ras del suelo, un poquito pragmáticas. ¿Debemos rezar por las vocaciones religiosas, para que todavía sigan en los hospitales, en los asilos, por esas personas que no están con el reloj en la mano? ¿Será este el distintivo? ¡Pero esto es a lo estamos progresivamente empujados!

En el fondo está también el exfoliarse del código institucional. Alain Touraine ha escrito en un hermoso libro, interesante, sobre el problema del multiculturalismo, una frase que cito: «Vivimos en un mundo de mercados, comunidades e individuos; ya no en un mundo de instituciones. El mismo término que ha sido la clave de la bóveda de la sociología clásica, se va resquebrajando, en cuanto que las prácticas superan las reglas. Entonces las figuras institucionales pierden valor. Resisten muy poco. En el campo eclesiástico sólo hay una que ha resistido, pero no sé si ha resistido porque es institucional o porque quien la ha interpretado ha sido capaz de hacerla resistir -elegid vosotros-. Habéis entendido de qué estoy hablando... Después las figuras, como figuras institucionales, valen dentro de nuestro mundo (sociedad sistémica auto-referencial). Al margen de nuestro recinto, la capacidad institucional de estas figuras significa poco, muy poco, en cuanto figuras institucionales. Si se sostienen, se sostienen en la propia capacidad, y esto naturalmente evidencia otro error fundamental: ya no es posible hablar de vocaciones a tareas eclesiales relevantes si no están cultivadas por personalidades fuertes. He dicho aposta "si no están cultivadas", porque no me refiero al hecho de que entonces sólo se pueda elegir a esos que ya la tienen. Creo en la fuerza de la educación, de la cultivación. Es verdad que ha de tener un mínimo. No todos se convierten en Giotto, no todos llegan a ser Einstein, pero uno bien cultivado puede llegar a ser un buen pintor, un buen matemático, un buen físico. Pero este cultivo es necesario. Pero, si me lo permitís -visto que este es mi trabajo primero y principal- me parece ver en el bajofondo eclesial la idea 
que, por ejemplo, «estudiar... sí, hay que hacerlo, porque no hay más remedio que tirar para adelante durante esos años y hacer esos exámenes... pero esto, con la vida de la Iglesia, no tiene mucho que ver...». A mi parecer, esto es dramático. Entiendo que quizás, en el caso específico, depende también del hecho de que deberíamos hacer una teología mejor, de acuerdo; pero en este mundo nuestro, atribuir una tarea de figura de referencia a una persona que no tiene perfil, significa condenarlo a una vida infeliz y significa generar su esterilidad, porque ya no será capaz de producir.. ¡Quizás pueda clonarse! Pero no generará vocaciones. Y no es una broma o un juego de palabras.

Es, pues, necesario mirar con mucha atención al horizonte, hay que volver a plantear con fuerza el interrogante, la capacidad de encarar los problemas fundamentales. Ya lo decimos con tiempo, ¿por qué nuestra gente, cuando tiene problemas de fondo acerca de ciertos interrogantes, con mucha frecuencia va a llamar a tantas puertas que no son las nuestras? No es una cosa nueva, lo he encontrado en Pascal, en los Pensamientos, cuando, grosso modo, dice: Había empleado mucho tiempo en el estudio de las ciencias abstractas, pero en cierto momento estaba disgustado porque no podía comunicarme con los demás. Entonces comencé el estudio del hombre, y pensaba que podría hablar de ello con los otros... creía al menos que encontraría muchos compañeros en el estudio del hombre... ¡Me equivoqué! Son incluso menos que los que estudian matemáticas.

Es posible que encontremos dificultades para tener este coraje, pero no podemos patear la carretera de las emociones fáciles, esto es, no auténticas. Las emociones son importantes. Pero precisamente porque son importantes, son una cosa seria, y nunca son las que cubren el vacío de la cabeza.

\section{La hipertrofia del sujeto}

Estamos en una sociedad de sujetos, de "singles". La explosión de la subjetividad es el producto del iluminismo y en la última modernidad es también la retorsión tremenda que conduce al fin del sujeto. Resumo todo en una imagen: Prometeo, Narciso, Ulises. Por el iluminismo ha sido vestido por Prometeo y mantiene esta semejanza animado por éxitos estrepitosos de las ciencias sobre todo aplicadas, y por la técnica. Pero cuando se mira al espejo, su rostro es como el de Narciso. Porque sólo se reconoce a sí mismo, no logra abrirse a los demás. Todo se juega en la forma de la referencia a sí mismo y no a la de la relación. ¿Qué dicen nuestros muchachos? “¡Cuánto me siento!”, "Me encuentro bien con...". Este es el juicio moral: la moral del gusto (me place), y así sucesivamente. Uno está, mientras está bien, después cuando no está bien cambia. Ahí está Narciso, con todo lo que consigue con esto, pero dentro de sí mismo - no en todos los casos, pero con frecuencia- todavía vive 
la inquietud de Ulises. Una inquietud que le lleva no a mirar en lo profundo, sino a vagar en una especie de nomadismo espiritual. Naturalmente son generalizaciones, quede bien claro, cada uno a sí mismo. Pero son rasgos relevantes. Como decía Martin Buber: «El hombre de nuestro tiempo es como un viandante que lleva su tienda en su zurrón y ni siquiera sabe dónde plantar los palos». En el centro ya no está la realidad. En el centro está el sujeto. Y entonces está claro que esto comporta una dificultad radical para imaginar una proyectualidad de vida que establezca los propios rasgos identificando el centro con una exposición de sí mismo. Es una autorrealización que hace el sujeto girando sobre sí mismo. Es un Ulises que no tiene una meta, que no está volviendo a Ítaca, ni siquiera está yendo a descubrir, más allá de las columnas de Hércules, mundos desconocidos. Es el Ulises inquieto, atormentado y, por consiguiente, siempre volviendo sobre sí mismo, desde Joyce hasta ahora.

A esto se une ese rasgo último de mirada al horizonte que es la pérdida de la visión de futuro. A mí esto me parece el aspecto más dramáticamente inquietante del viraje de la última treintena. Hasta el sesenta y ocho se ha vivido la historia de occidente como una historia progresiva. Incluso cuando la cultura difusa ha abandonado la idea de un andar al encuentro del Señor que viene, de una idea eterna, la ha mantenido, desvestida de todo contorno escatológico y religioso, como tensión en el progreso. Incluso Marx mantiene esta dinámica típicamente bíblica de ir hacia: hacia la sociedad perfecta, la sociedad sin clases. Existe un mesianismo en todo esto, aunque se haya quedado sin Mesías. La última treintena, por el contrario, ha señalado un corte dramático. La mentalidad común ya no va "hacia", por eso nuestro tiempo es rico de capacidad programática y extremadamente pobre de capacidad proyectual. Navega al alcance de la mirada. Este es un engaño formidable. No podemos pensar en el resurgir de vocaciones, en general - esto afecta a cualquier clase de elección, la familia, por ejemplo-, que tengan consistencia, cuando la idea de fondo es esta, la convicción difusa es esta.

\section{Las transformaciones de la familia}

Muchas veces pensamos que ciertas elecciones, ciertos decaimientos -pensemos en la familia-, se deben a un descenso de la catadura moral de las personas. Pero ni por sueño, ¡no es verdad! Somos nosotros porque somos unos moralistas incurables. Existen condiciones completamente distintas, sobre todo sociales, por lo que se refiere a la familia, como es fácilmente comprensible: la familia unida y numerosa es funcional para un cierto tipo de sociedad y de economía. Este tipo de sociedad y economía ya no existe, por tanto estos elementos no se mantienen, emergen otras dinámicas, que siempre las ha habido, pero coartadas por este estancamiento. Desde el punto de vista 
cultural existe la idea de hacer algo, existe la idea del abuelo que planta, entierra la pequeña planta, porque la verán los nietos. Tenemos todavía esta idea, esto es, esta capacidad desde el punto de vista a flor de tierra, desde el punto de vista humano, concreto, de ver las cosas en perspectiva, a largo alcance. Caemos en la cuenta de que éste no es el modo actual de pensar.

Entonces se entiende que después las realidades, las uniones se hacen temporales. Son necesariamente temporales, en esta cultura. Si no se vence esta cultura, si no ponemos ante el hombre la esperanza ("Cruzar el umbral de la esperanza"), el futuro, si no ponemos nuestro futuro, que es el adventus, esto es, el hecho de que el Señor viene, que el Reino se ha hecho cercano, si no restauramos esto -no como palabra, sino como convicción y mentalidad difusa- tendremos inexorablemente opciones frágiles.

He ahí entonces una de las insidias que afectan a las vocaciones porque afectan a las familias. La familia está desguarnecida socialmente, está desguarnecida culturalmente. Su desamparo cultural es todavía más dramático, porque "familia" se ha convertido en el nombre de muchas cosas, diferenciadas entre sí. Es inútil poner ejemplos, porque todos los conocemos. Si consultáis los sondeos - que no son el evangelio, ni siquiera son la verdad revelada, pero ayudan a entender, tomados "cum grano salis"- (por ejemplo dos o tres de los últimos siete/ocho años) vemos la valoración moral de la convivencia y del aborto. Os daréis cuenta que la convivencia es considerada inmoral por un tercio de las personas que consideran inmoral el aborto. Me parece que es un dato suficientemente significativo. Y daos cuenta de que en los últimos tiempos ha habido un ligero incremento de las personas que consideran el aborto negativamente, por tanto no se ha descendido. Pero, en cuanto a la convivencia, quien la considera decididamente inmoral en el ámbito juvenil en Italia es poco más del $10 \%$. Por tanto existe esta debilidad cultural y entendéis que lo que está debajo de la idea de convivencia es precisamente la idea de temporalidad, de no decisión, que inflige una herida mortal a todo discurso de carácter vocacional.

Entonces está claro que recogemos inmediatamente una idea de fondo: está claro que hoy la pastoral de las vocaciones específicas existe solamente si tiene consistencia educativa la dimensión vocacional de la existencia cristiana, y de la existencia humana "tout court", esto es, si se incardina en una antropología en la que el hombre, la persona humana es considerada como respuesta a una llamada a la vida, llamada a la acción, a la realización, a la relación con Dios y con los otros. Solamente dentro de esta dimensión es posible hablar de otras dimensiones. Pero esta dimensión es rebelde, y frágil.

Entonces, para descender a lo concreto, en nuestros recorridos, en nuestra catequesis, en la poca que existe, tenemos que rehacer todos los programas, porque hay prioridades que hay que perseguir; no podemos ir adelante 
diciendo: «Explicamos esto, después explicamos eso otro, después explicamos eso otro...». Hacemos reír hasta a los pollos, es ridículo. Después nos sorprendemos de que al final no saben nada. Probadlo. Yo lo pruebo con los muchachos, voy todas las semanas a una escuela, pregunto los mandamientos ¡no los saben! ¡Los mandamientos! Para nada les he preguntado los dones del Espíritu santo, que es un poco más complicado. Pero no los saben. Probadlo. Yo se lo hago decir siempre. Al final quizás al menos los mandamientos... Después hay que ver si uno que los sabe los pone en práctica, pero saberlos ya es algo. ¡Y nos sorprendemos! Lo digo siempre: después de ocho años de enseñanza de la religión, ¿qué nivel tienen? ¡Simplicísimo! A la pregunta: ¿Quiénes son los cuatro evangelistas?, la respuesta es: "Los cuatro evangelistas son tres: Mateo y Marcos”. ¡Este es el nivel! Y no se llega más allá.

Entonces debemos intentar establecer unas prioridades, insistir; si nos interesan de verdad las vocaciones, nos tiene que interesar por fuerza su problemática... estos niños, estos adolescentes, cuando oyen las cosas que les decimos, ¿adquieren la idea de que la vida es un don que hay que desarrollar? Que, por tanto, si es un don, ¿significa que dentro hay una relación, que es una "llamada a"? Porque si no logramos comunicar esto -y junto con esto otros razonamientos, pero esto es un razonamiento, absolutamente un razonamiento- todo el resto de la reflexión vaga en el vacío, no se agarra por ninguna parte. Entonces, si digo que la dimensión vocacional es estructural, no lo digo porque me toca hablar aquí ahora. Es porque es así. Entonces hay que "combatir", actuar fuertemente para que en nuestros procesos educativos esto emerja, tome consistencia. La "cuestión antropológica" no es una palabra solemne, es una realidad simple -a veces complicada, pero en este caso, simple-, esto es, lograr hacer percibir esta dimensión fundamental, radical de la existencia.

Otro aspecto que afecta a la familia es el propagarse del contractualismo. Toda nuestra vida social está regulada por el contractualismo. Habiendo perdido el valor de referencia, sólo podemos ponernos de acuerdo, para intentar no sacarnos los ojos los unos a los otros. Este es el contractualismo -dicho de una manera un poco brusca, pero grosso modo es así-. El contractualismo se ha infiltrado también como mentalidad de la familia. Con demasiada frecuencia. Esto es, una serie de "yo te doy esto para que tú me des eso", y de todos modos la idea de que la suma total esté, como en todos los contratos, ligada a la realización de algunos beneficios y definida por un cierto arco de tiempo.

Cuando leemos que la familia "se mantiene", que la familia en Italia "se mantiene", es uno de esos casos en los que, si queremos los espejuelos para caza de alondras, acomodémonos ... si queremos que alguien nos diga las cosas que queremos oír para estar tranquilos, sí, acomodémonos... No es verdad. Hay un dato de hecho: en Italia todavía hay una idea fuerte de la familia como grupo de referencia y, por tanto, la familia ejerce en Italia funciones que 
ya no ejerce en otras naciones. ¡Hasta lo paradójico! Podría citar un par de sentencias del Tribunal supremo sobre el deber de mantener los hijos hasta los noventa años, o poco menos... Esta es una paradoja totalmente italiana. Pero hay que estar bien atentos, es una función de descargo y de compensación dentro de la cual el valor de la familia, tal como lo entiende la fe cristiana, no está. Es una figura social, psicosocial que vale dentro de una cierta trampa, que da la apariencia, pero sólo la apariencia, es tan verdad esto que cada día más las cifras nos dicen hacia dónde camina la familia, también en Italia. Esta cosas son importantes para no dejarse engañar.

Una familia débil no puede generar vocaciones estables, una familia inestable no genera vocaciones estables; luego está el Espíritu santo..., también hace esto, en casos singulares, pero generalmente el cuidado de la familia es fundamental desde el punto de vista de las vocaciones. Lo decía al principio: se sostienen una a la otra indisolublemente.

Entonces es necesario trabajar juntos mucho más -como decía don Luca Bonari en su introducción-, es absolutamente necesario, porque son de verdad realidades que "aut simul stabunt, aut simul cadent".

Después también ocurre que lees una voz entera,bastante larga (doce páginas), de un voluminoso diccionario de la vocación, donde la familia no se ve, ni siquiera se la cita, como si se pudiese hablar de vocaciones que bajan de los alto por vía angélica y prescinden totalmente del contexto. En realidad las cosas no son así. Como decía el papa en la Familiaris consortio, número 53: «La familia que vive ideales y valores espirituales, que sirve a los hermanos con disponibilidad y alegría, que cumple sus específicas responsabilidades con fidelidad y perseverancia, seguramente esta familia es el terreno bueno en que pueden nacer y desarrollarse vocaciones a una vida de consagración por el Reino de Dios». Debería darse por supuesto, pero hay que trabajar para esto; sobre todo en una familia que se ha hecho familia que, incluso cuando es cristiana -por tanto cuando resiste a esos condicionamientos sociales y culturales que he dicho antes-, se encuentra en dificultad. ¿Por qué? Porque muchas veces es una familia con escaso número de hijos, o incluso con un hijo único. Yo puedo decirlo porque soy hijo único. Cuando me fui al seminario mi padre no me habló durante un año. No porque fuese contrario a esto en cuanto "elección", sino porque veía sus proyectos malogrados. Este problema no lo tienen las familias numerosas. Entonces hay que sostener y ayudar, no basta decir: "Sed generosos...", hay que intentar poner las condiciones, que son -según mi parecer- ayudar a estas familias a integrarse las unas con las otras, intentar superar este secuestro espantoso que impone tantas penalidades a la formación de los hijos en tanto sentidos, e incluso hace replegar peligrosamente a la familia. También el proteccionismo pedagógico, como compensación justificativa de la obsesión parental, es una de las formas 
que hoy ha asumido la familia, una de esas que promueve el narcisismo débil y entonces permite, como mucho, vocaciones de la emoción pero no del discernimiento y de la decisión.

\section{Los jóvenes}

Habría mucho que decir. Esta generación nuestra se ha definido de muchas maneras. Se ha dicho, en un informe reciente sobre Italia, que tiene las pilas gastadas... y desde hace tiempo los sondeos sobre los jóvenes evidencian su desconfianza, su desilusión. El problema de los jóvenes son los adultos. Esto es, somos nosotros, los adultos. Y ha llegado el momento de decir que los jóvenes no son un problema... el problema viene de nosotros. Hemos de tener en cuenta esta compleja situación. Los jóvenes de hoy no son peores que los de ayer, no tienen menos ideales, pero encuentran menos estímulos, menos aperturas, menos apoyos. De hecho tenemos un dato que es verdaderamente lamentable: el $41,4 \%$ en los últimos sondeos -me refiero al del nivel europeo, pero en el segmento italiano- dice que la religión es poco o nada importante. Y estemos atentos porque este dato va unido al otro que, por el contrario, es el aumento de la religiosidad: Dios es importante, pero no la religión. Desde el sondeo del '90 hay un incremento de alrededor de 5 puntos sobre la importancia de Dios en la vida, y un decrecimiento de estos 5 puntos sobre la importancia de la religión. Esto confirma el dato sobre la institución, y nos dice que nuestra imagen está deteriorada, como la FIAT... no vende. Hay un conjunto de factores; pero no hay duda de que no logramos comunicar nosotros mismos, Iglesia, realidades específicas de la Iglesia, como un camino abierto para satisfacer esta demanda religiosa que ha aumentado en el último decenio. Antes hacía referencia a la única figura institucional que se sostiene, y esto explica ese fenómeno extraordinario que son las Jornadas Mundiales de la Juventud. Las catas lo confirman. Y, sin embargo, esta escasa capacidad, con un rebote de desilusión, de no encontrar en las realidades eclesiales concretas, las de cada día, ciertamente no los centenares de miles de personas, pero algo que se asemeje; de encontrar una repetición cansada. Este aspecto me parece importante.

\section{Algunas propuestas concretas}

\section{Incidencia cultural}

Sobre todo hay que trabajar sobre el horizonte cultural, en el sentido de cultura difusa, no de la cultura docta, esto es, sobre la mentalidad. He citado distintos puntos. Tenemos que tener el coraje de trabajar para tiempos largos, 
porque este aspecto exige tiempos largos. No se modifica una cultura difusa con la varita mágica. Por tanto, no caigamos en la tentación del todo e inmediatamente, que es lo que caracteriza drásticamente nuestro tiempo, no dejemos de trabajar a tiempos largos para todo eso que puede incidir o que podrá incidir en la formación de la mentalidad.

Los campos son muchos, como sabemos, por la comunicación a la escuela, tan desatendida: tengo la idea fija de la escuela... tan desatendida y tan fundamental. Es verdad, ahí está esa gran agencia que es la televisión, pero la escuela sigue siendo un punto fundamental, y me gustaría que alguien me dijera de una bendita vez que existe una parroquia en la que la escuela entra en la pastoral ordinaria... aún no la he encontrado, cuando la encuentre cantaré el Te Deum... Esta es una insensatez, no podemos pensar cultivar vocaciones en algunos rincones del mundo... se cultivan desde dentro de la realidad concreta, esa que de verdad frecuentan los jóvenes, las jóvenes, los muchachos, en los lugares que ellos habitualmente frecuentan, y la escuela es uno de estos. No podemos, no debemos abandonar la escuela, y no podemos conformarnos sólo con hacer documentos.

La intemperie cultural. No tener miedo. Sostener, también desde el punto de vista de la imagen, a los que se exponen con la propuesta cristiana, que hoy es radicalmente impopular. Lo he dicho desde el principio: No para ponerse a contrastar -si no es necesario-... cuando es necesario, ¡también esto!-. Alguna señal aquí y allá se ve de vez en cuando. Es importante sostenerlos, es importante seguirlos, es importante actuar en este tiempo, y por eso, naturalmente, hay que trabajar, hay que profundizar - perdonad la deformación profesionalhay que estudiar, porque nadie ha nacido "instruido", hay que actuar de manera que de verdad podamos decir cosas de peso, cosas frente a las que se pueda decir: "No estoy de acuerdo", pero que no se pueda decir: "Estupideces, una cosa que no vale nada". Este es el punto. Frente a la propuesta de la fe cristiana, nadie tendría que decir: "Es una cosa de cuatro perras, que va bien para cuatro mujerucas desdentadas", y de ahí para abajo, con todo el respeto para esas mujeres desdentadas. Este es un punto fundamental y radical.

\section{La comunidad cristiana}

La forma de la comunidad cristiana. Nunca habíamos hablado tanto de comunidad como en la última treintena. Evidentemente porque no existe. Porque se habla siempre frecuentemente de lo que se querría que existiera y que no existe.

Es necesario que la dimensión vocacional caracterice, como improrrogable prioridad pastoral, el compromiso de nuestras comunidades cristianas. No es principalmente un tema que se añade, sino un horizonte, una perspectiva, 
una tonalidad, una cualidad. Tiene que entrar en el contexto de las homilías, de los coloquios, de la dirección espiritual. Debe ser un horizonte, un color.

Otro aspecto. Es necesario pasar del "estancamiento", según la lógica del mercado, al repunte de imagen, según la perspectiva del testimonio de evangelización. Si se miran los números: "En el fondo, es como la bolsa de los últimos dos años, hoy no se ha perdido tanto"... después de hacer las cuentas al final de año: $-25 \%$. Pasar del "estancamiento" - del "pero si, todavía tenemos..."- al repunte de imagen, una pastoral verdaderamente de testimonio y de evangelización. Dejar "cercenar", por lo menos, la "pastoral de los clientes" en la que nos hemos precipitado. Vienen, nos preguntan esto, cuánto cuesta, etc. El joven, también el joven consumidor, no perdona esas instituciones "simbólicas" que caen en el sistema mercantil. La pastoral de los clientes, de la demanda y de la oferta, produce (o alimenta) la mentalidad del consumidor y la mentalidad del consumidor consume también las relaciones. No puede convertirse en la lógica de la pastoral.

Otro aspecto. Desarrollar la pastoral de acogida. Significa partir principalmente de la conciencia de que esos que son de casa en nuestras casas es una minoría exigua. Porque nosotros seguimos diciendo que se ha terminado la homogeneidad cristiana, y seguimos practicando en todos sus puntos una pastoral de homogeneidad cristiana. Decir "pastoral de acogida" no significa sonreír, significa comprender la dificultad del otro. Un párroco de Roma contaba una misión en distintos ambientes... «Hemos hecho la misión en mi zona, zona comercial, han participado muchos, han sido activos... He pensado: Entonces organizo también en la parroquia una cosa similar. Los invito a un encuentro». ¿Cuántos han ido? Nadie. Entonces ¿simulaban? No. Es como ir a un territorio desconocido... uno tiene miedo, no se expone. Caigamos en la cuenta de esto, tenemos que caer en la cuenta.

Pastoral de acogida significa desarrollar modalidades concretas de acercamiento, de comunicación, de relaciones -porque la pastoral está hecha de relaciones- que venzan esta situación de extrañeza. A no ser que pensemos todavía como aquel párroco que, cuando llegan los dos novios que querrían casarse, dice: “¡Pero a vosotros jamás os he visto!”. Como si no tuviera que decirse a sí mismo: "Pero tú ¿dónde estabas? ¿por qué no sabías que existían estos?". Es la inversión de esta mentalidad, es una infraestructura esencial, para que emerja de nuevo la relación eclesial dentro de la cual nacen las vocaciones. Creo que ninguno de los presentes se ha hecho a sí mismo, desde el punto de vista eclesial. Todas son vocaciones que nacen del contacto con los sacerdotes, religiosas, frailes, activos, comprometidos, contentos, contentos con lo que hacen. Sin esta relación no es posible. Esto, desde distintos puntos de vista, exige una ministerialidad más articulada; quiere, por otra parte, que se supere la tentación de la pequeña grey. Un autor norteamericano, traspasa- 
do después a Nueva Zelanda (George Halzedon), ha propuesto una ciudad cerrada, Heritage Park, cerrada y protegida. La tentación de la pequeña grey: «Las comunidades-gueto, que se asemejan más a orfanatos, prisiones o manicomios, que a lugares de libertad» (Phil Cohen). La comunión no es hija del reduccionismo pastoral, del hogar-puede ir bien, si enciende otros fuegos, si no intoxica-. La comunión es recorrido ascético que exige todo lo que exige un recorrido ascético.

Hay que proponer comunidades adultas. Una de las definiciones más centradas de nuestra sociedad es "la sociedad de la gratificación instantánea" (Gerard Schultze). El mundo juvenil está marcado por esto. Y quizás no sólo el mundo juvenil. Ser adultos significa haber superado eso que es típico de la adolescencia. Estamos invadidos por adolescentes empadronadamente obsoletos. Es necesario que consigamos construir comunidades adultas, esto es, hacer crecer personas. Y entonces quizás hay que revisar el modo de hacer el grupo. Elementos - diríais vosotros- que ya se conocen. No he descubierto nada nuevo. Pero ciertamente también la capacidad de descubrir talentos, y eso también es importante, de comprometer a las personas. Yo no estaría aquî si un vicario parroquial no me hubiera invitado a ayudar como catequista, a ir a la escuela parroquial, a hacer esto y lo otro... No hay que decir que haciendo esto salga un cura, pero... es importante entender cómo están hechas las personas, valorar sus aspectos. La vocación cristiana es multiforme, y por tanto obrar de tal manera que se entienda que, en la Iglesia, los tipos, las tipologías no son enyesados, moldes, sino que son referencias dentro de las cuales existe la posibilidad de expresarse creativamente, y esto toca a nuestras comunidades. Está claro que si adoptamos la praxis por la que, si la persona es apta para mover los vasos, y yo le hago mover botellas, porque así crece en la virtud, según una cierta espiritualidad conocida a muchos de los presentes... Que uno deba estar dispuesto a mover las botellas, aunque haya nacido para mover los vasos, pertenece a la espiritualidad; pero que el superior actúe de esa manera, no pertenece ni a la espiritualidad ni a la inteligencia. Hace falta que emerja este aspecto. Esto es, el aspecto de que el dedicarse a la vida de la Iglesia es algo hermoso incluso para el desarrollo de la propia persona, si se siente llamado a hacer esto, es obvio. Sabiendo que nadie puede pensar en recortar su hornacina. Entonces es necesaria esta capacidad de identificación.

No a las propuestas débiles; no a las propuestas maximalistas; ya tenemos bastantes fanáticos, no hay necesidad de aumentar el número. Las propuestas fuertes no son las de los fanáticos, son las de los que tienen una estructura, y se sabe bien que quien tiene una estructura es capaz también de cambiar, como siempre han dicho los antiguos: "Sapientis es mutare consilium" -... pero no cada cinco minutos-. Por tanto, personalidades robustas, que crecen, que se proyectan. 
Todavía no he dicho una cosa, con la que casi termino. Está claro que hay que rezar. ¡Es cierto! Lo ha dicho Jesús, por tanto no hace falta otra autoridad, no hay necesidad de argumentar, es suficiente. Este es un camino que siempre va bien y que no puede olvidarse, porque si este camino no lo recorremos, todo lo que he dicho hasta ahora y todo cuanto pudiera decirse, probablemente no serviría para nada.

Orar. Pero quisiera precisar. No porque llame, sino porque manda. Porque me parece que el evangelio lo dice así. El Señor llama, pero me parece -si lo interpreto mal me lo hará entender antes o después- que a veces es poco respetuoso con nuestra libertad. Entonces hace falta rezar para que venza esa renuencia suya a sacudirnos. Puede parecer una violencia, pero si abro la Biblia, encuentro a Amós (capítulo 7) que, al sacerdote Amasías que le pregunta qué ha venido a hacer a Betel, le responde: «Yo no soy un profeta profesional. Yo cuidaba bueyes y cultivaba higueras. Pero el Señor me agarró y me empujó hasta aquí”. ¡Que el Señor mande! Quisiera hacerme eco, en otro sentido, de una observación que ha hecho el Papa, y que me ha puesto lo pelos de punta, «quizás Dios se ha "cansado" un poco», pues que no se canse de nuestras negativas. Me acuerdo de Jeremías cuando protesta: «Me has violentado». Pues rogar para que Dios vuelva a violentar. Finalmente me acuerdo de Jonás, que me parece un icono casi perfecto de nuestra pastoral, temerosa de meterse en la gran ciudad, Nínive, y entonces mejor retirarse disimuladamente. ¡Que todavía eche a alguno al mar! Después, ojalá, mientras lo hacemos para los otros, quizás, no sea inútil que nos metamos dentro también nosotros mismos, porque ya no nos sentimos llamados, porque si la vocación de Dios pertenece al pasado, corre el riesgo de ser una vocación muerta. Pues también la nuestra debe mirar al futuro. 